\title{
Enterprise Modelling for the Masses - From Elitist Discipline to Common Practice
}

Sandkuhl, Kurt ; Fill, Hans-Georg ; Hoppenbrouwers, Stijn ; Krogstie, John ; Leue, Andreas ; Matthes, Florian ; Opdahl, Andreas L ; Schwabe, Gerhard ; Uludag, Ömer ; Winter, Robert

\begin{abstract}
Enterprise modelling (EM) as a discipline has been around for several decades with a huge body of knowledge on EM in academic literature. The benefits of modelling and its contributions to organizational tasks are largely undisputed. Thus, from an inside-out perspective, EM appears to be a mature and established discipline. However, for initiating serious innovations this view is not sufficient. This position paper takes an outside-in perspective on enterprise modelling and argues that EM is far away from reaching its maximum potential. EM is typically done by a limited number of people in organizations inclined to methods and modelling. What is captured in models is only a fragment of what ought to be captured. Many people actually develop some kind of model in their local practice without thinking about it consciously. Exploiting the potential of this "grass roots modelling" could lead to groundbreaking innovations in EM. The aim is to investigate integration of the established, often systematic and formalized practices of modelling in enterprises with local practices of creating, using and communicating modellike artifacts or objects of relevance for the overall organization.
\end{abstract}

DOI: https://doi.org/10.1007/978-3-319-48393-1_16

Posted at the Zurich Open Repository and Archive, University of Zurich

ZORA URL: https://doi.org/10.5167/uzh-126989

Conference or Workshop Item

Originally published at:

Sandkuhl, Kurt; Fill, Hans-Georg; Hoppenbrouwers, Stijn; Krogstie, John; Leue, Andreas; Matthes, Florian; Opdahl, Andreas L; Schwabe, Gerhard; Uludag, Ömer; Winter, Robert (2016). Enterprise Modelling for the Masses - From Elitist Discipline to Common Practice. In: 9th IFIP WG 8.1 Working Conference on The Practice of Enterprise Modeling, Skövde, Sweden, 8 November 2016 - 10 November 2016, Springer Lecture Notes.

DOI: https://doi.org/10.1007/978-3-319-48393-1_16 


\title{
Enterprise Modelling for the Masses - From Elitist Discipline to Common Practice
}

\author{
Kurt Sandkuhl ${ }^{1}$, Hans-Georg Fill ${ }^{2}$, Stijn Hoppenbrouwers ${ }^{3}$, John Krogstie ${ }^{4}$, \\ Andreas Leue ${ }^{5}$, Florian Matthes ${ }^{6}$, Andreas L. Opdahl ${ }^{7}$, \\ Gerhard Schwabe ${ }^{8}$, Ömer Uludag $^{6}$, Robert Winter ${ }^{9}$ \\ ${ }^{1}$ University of Rostock (Germany), kurt.sandkuhl@uni-rostock.de \\ ${ }^{2}$ University of Vienna (Austria), hans-georg.fill@univie.ac.at \\ ${ }^{3}$ HAN University of Applied Sciences (The Netherlands), stijn.hoppenbrouwers@han.nl \\ ${ }^{4}$ Norwegian University of Science and Technology, john.krogstie@ idi.ntnu.no \\ ${ }^{5}$ Sphenon GmbH (Germany), a@leue.net \\ ${ }^{6}$ Technical University of Munich (Germany), [matthes, uludag] @tum.de \\ ${ }^{7}$ University of Bergen (Norway), Andreas.Opdahl@uib.no \\ ${ }^{8}$ University of Zurich (Switzerland), schwabe@ifi.uzh.ch \\ ${ }^{9}$ University of St. Gallen (Switzerland), robert.winter@unisg.ch
}

\begin{abstract}
Enterprise modelling (EM) as a discipline has been around for several decades with a huge body of knowledge on EM in academic literature. The benefits of modelling and its contributions to organizational tasks are largely undisputed. Thus, from an inside-out perspective, EM appears to be a mature and established discipline. However, for initiating serious innovations this view is not sufficient. This position paper takes an outside-in perspective on enterprise modelling and argues that EM is far away from reaching its maximum potential. EM is typically done by a limited number of people in organizations inclined to methods and modelling. What is captured in models is only a fragment of what ought to be captured. Many people actually develop some kind of model in their local practice without thinking about it consciously. Exploiting the potential of this "grass roots modelling" could lead to groundbreaking innovations in EM. The aim is to investigate integration of the established, often systematic and formalized practices of modelling in enterprises with local practices of creating, using and communicating modellike artifacts or objects of relevance for the overall organization.
\end{abstract}

Keywords: Enterprise modelling, grass roots modelling, research roadmap

\section{Introduction}

Enterprise modelling as a discipline in academic research and as a practice in organizations has been around for several decades. The body of knowledge represented by academic publications is huge and includes modelling methods, metamodels, notations, experiences, practice recommendations, organization aspects, value considerations and much more (cf. Section 4). The benefits of modelling and its contribution to organizational tasks, like business model development, visualization of the current situation, strategy development or business and IT alignment, and 
enterprise architecture management are largely undisputed in IT-related research. New challenges for the discipline are addressed by ongoing research work [1] and will eventually be taken up by industrial practice. This inside-out view of enterprise modelling as an established and quite mature discipline might be somewhat idealistic, but is shared by many people in the discipline [2]. However, for initiating serious innovations this view is not very helpful because it fails to address some very serious hindrances to actual, large-scale adoption of modelling in practice, e.g., people refuse to spend time creating and maintaining enterprise models, find modelling and modelling methods complex and cumbersome, or do not immediately see its use for their particular perspective or set of concerns.

The authors of this position paper prefer an outside-in perspective on enterprise modelling and argue that EM is far away from reaching its maximum potential, has yet to prove its benefits for the majority of business stakeholders and is not missioncritical for an enterprise (cf. Section 2). Enterprise modelling is typically done by only a few people in the organization who are inclined to methods and modelling /cf. Section 4.1). What is captured in models by this small group and made available for organizational purposes is only a fragment of what ought to be captured, discussed and communicated. Many people actually develop some kind of model without thinking upon it as modeling [3, 4]. Examples are spreadsheets ${ }^{1}$ used to capture essential features of products and their dependencies, presentation slides with architecture sketches and process descriptions, mindmaps or sketches in drawing tools defining the information flow in a business service. The content of such documents often is highly valuable to the stakeholders in the enterprise but difficult or even impossible to retrieve [5]. It is content which often meets all characteristics of a model (e.g., abstraction, reduction for a purpose at hand, pragmatic use for a defined stakeholder) but the model content is buried in a document format, or is even totally unstructured. The content is created by a domain expert who is doing her/his job and who is probably not explicitly interested in enterprise modelling in the traditional sense. Exploiting the potential of this "grass roots modelling" instead of expert modelling and usage of the unexplored content in existing, non-modelling documents and conversations could lead to groundbreaking innovations in EM as a discipline and a severe upgrade in EM's importance for practice. The aim is to investigate integration of the established, often systematic and formalized practices of modelling in enterprises with local practices of creating, using and communicating model-like artifacts or objects of relevance for at least parts of the overall organization.

This position paper elaborates on the vision of "modelling for the masses" by discussing the problem (Section 2), defining the vision (Section 3), describing the state of practice in enterprise modelling and beyond (Section 4), identifying the dimensions of the challenge and proposing topics for future work (Section 5). The main contribution of the paper is an analysis of the situation of EM use in organizations and potential ways of increasing its potential by "grass roots modelling". Both contributions need discussion in the enterprise modelling community. To kick off this discussion is the primary objective of the position paper.

\footnotetext{
${ }^{1}$ Much data relevant for engineers and other business professionals is developed and resides in office automation tools like Excel [5]
} 


\section{The Problem}

Starting from the hypothesis that there is a lot of unexploited potential of EM which would require a wider integration of local practices, this section explores causes for the current "problem" in EM from the perspectives of driving stakeholder concerns and sustained model utilization. Stakeholder groups that have a holistic, long-term perspective (like, e.g., IT or corporate management stakeholders), believe or at least should believe that architecture is no emergent feature of a complex system, but needs to be explicitly planned, implemented, controlled and adjusted [6]. Their concerns require models to cover multiple aspects, to cover a large number of artifacts, to ideally cover complete artifact life cycles, and to be coherent - the traditional motivation for EM and its use in enterprise architecture management. The EM discipline matured over the last decades by [7]:

1. diversifying its modelling object from IT infrastructure and software over IT applications, business processes and organizational structures to strategic positioning,

2. widening its modelling scope from single solutions over functional/business areas to enterprise-wide or even cross-enterprise models,

3. extending its scope from single object layer (IT artifacts or business artifacts) to the entire business-to-IT stack (Enterprise Architecture), and

4. representing not only as-is or to-be systems states, but also roadmaps or scenarios in order to cover the entire life cycle [8].

In contrast to the above mentioned 'enterprise-wide' concerns of certain stakeholder groups, most other stakeholder groups in organizations have interests that are more focused or short-term. They mostly prefer an opportunistic systems development process with architecture being an 'emergent' feature. Their concerns require models that cover selected aspects, comprise only artifacts that are 'locally' relevant, focus on their current design problem, and do not necessarily have to be fully coherent with other focus models. As a consequence, a plethora of 'local' models [9] can be found in organizations that are used by only one stakeholder group for 'local' analysis and design, or that serve as boundary objects [10] between two stakeholder groups. The co-existence of different concerns in organizations leads to a co-existence of enterprise and local models at various levels of scope, rigor, and (potential) impact that are not necessarily coherent.

As the benefits of EM were increasingly appreciated by large, complex organizations, the EM discipline matured, and various 'architect' role models were established in such organizations. Although many architects aimed at positioning themselves 'between' corporate management, business/project owners and IT, their backgrounds and competency profiles often kept them close to the corporate IT function [11]. Recently, an MIT CISR study revealed that "more mature architectures do not necessarily lead to business value" $[12, \mathrm{p}$. 1]. In contrast to the historical value perception and impact increase of EM, a turning point might have been reached where additional EM effort is not justified by appropriate impact gains any more [7].

The MIT researchers believe that the capped impact results from the fact that EM is driven primarily by architects and is valued primarily by IT people, so that its effects in an organization are often limited to these stakeholder groups. EM can be thus considered an elitist discipline. It may be possible to reach other stakeholder groups with EM, e.g., by implementing tight governance mechanisms that enforce 
local model coherence and certain completeness requirements for local models, but such measures would not only require too much governance effort, they would also not gain acceptance with the "90\% of an organization" [13] that have primarily local, focused concerns.

One important aspect of the "problem" in EM is therefore to conceptualize lightweight EM approaches that do not necessarily focus on traditional EM qualities like completeness and coherence, but instead on usefulness and impact not only for architects and corporate IT, but also for the majority of organizational stakeholders that might benefit from more professional modelling to support their decentral, focused analysis and design problems. Another aspect of the "problem" in EM results from the fact that models are used for many different purposes. In [14], the following usage areas are included: model mapping, human sense-making [15], communication between different stakeholders, model analysis, quality assurance, model deployment and activation, systems development, model implementation and standardization. Many traditional applications of modelling are limited to one usage area, and thus provide limited value. On the other hand, the fuller long-term effects of modelling in and across organizations can be observed when one uses models over a longer time but also across areas of use [16]. For this to work, though, one has to have the longterm use in mind from the start and prepare for this, and have ways to mature models when beneficial to spread knowledge across the organization [17]. When trying to build upon models meant originally for sense-making in a limited group and turning them into organizational memory, one will often experience limitations in the original modelling approaches and modelling tools used [18]. Few people retain ownership over these models over a long time span so that models gradually decay, unless appropriate mechanisms are put into place to keep them alive and up-to-date as organizational practice.

Both aspects of the "problem" in EM point into a similar direction: The traditional understanding of enterprise models as an instrument of architects and certain roles in project teams to ensure qualities like coherence or alignment, have to be extended to better include many stakeholder groups with their decentral concerns and to cover a longer sustained life span (and thus enhanced value) of enterprise models.

\section{The Vision}

It can be argued that the main reason that humans have excelled, is their ability to represent and transfer knowledge across time and space, developing new knowledge on the way. Whereas in most areas of human conduct, one-dimensional (textual) languages, either informal (natural language) or formal (as in mathematics) have traditionally been used for this purpose, we see that the use of two and multidimensional representational forms is on the rise. Enterprise modelling is one such technique. For modelling to have a larger effect, we propose a move of technologies and approaches to also enable 'normal' knowledge workers to be active modelers, both by adapting the applications they are using to support their daily work tasks and by providing support for specific non-routine situations.

Our vision for the future of EM in an organizational context is as follows: 
Ten years from now, the majority of organizational stakeholders uses enterprise modelling (often without noticing it) to capture, store, distribute, integrate and retrieve essential knowledge of their local practices in a way that supports long-term, cross-concern organizational objectives.

This vision includes many aspects that need further elaboration and refinement, some of which are the following:

- Modelling is embedded in everyday work, not only a distinctive practice: Nonexperts in modelling do modelling, sometimes even without knowing it;

- Different kinds of model content, formats and purposes can be extracted (or mined), combined, integrated and federated on demand, either through primarily human intervention or driven by a symbiosis of humans and intelligent agents;

- Local practices in capturing knowledge can be specific yet integrative with other local practices;

- Modelling by non-experts (a.k.a. grass-root modelling) and professional modelling co-exist in synergetic use;

- Models are not primarily developed for one specific purpose, but can be more flexibly used for several purposes, e.g. by using viewing mechanisms to tailor the model for different usages;

- Completeness, coherence and rigor requirements to models and modelling languages in some contexts are softened towards possibilities for incomplete, partly formalized and contradictory model parts, and issue and approach being discussed in work of interactive models [19];

- Modelling is not an end, i.e. a purpose on its own, but a means to an end, e.g., for business model development, visualization of the current situation, strategy development, business and IT alignment, model mapping, human sensemaking, communication, model analysis, quality assurance, model deployment and activation, model implementation and standardization.

\section{State of Practice in Enterprise Modelling and Beyond}

For attaining the vision outlined in the previous section, approaches, methods and technologies from various areas in computer science, business information systems and social sciences will have to be involved, some of them already existing but many others to be adapted or even newly developed. This section identifies and briefly summarizes potentially relevant areas and sources of inspiration from enterprise modelling, knowledge management, model-based collaboration environments, gamification, semantic web, legal visualization, practice theory, CSCW and architectural thinking. This list of areas probably is not exhaustive. For each area, the relevance for the vision is briefly outlined. We structured the above areas into methodical and formal approaches (4.1), practice oriented approaches (4.2) and approaches relevant to tools support (4.3) to improve readability of the section. 


\subsection{Methodical and Formal Approaches}

\section{Enterprise Modelling}

In general terms, EM addresses the systematic analysis and modelling of processes, organization structures, products structures, IT-systems or any other perspective relevant for the modelling purpose [20]. A detailed account of EM approaches is provided in [21]. Participative modelling and involving different stakeholder groups in EM has a long tradition (see, e.g., [22]). Domain-specific modelling languages (DSML) [23] are supposed to support these various stakeholders in model creation and use. The scientific literature on EM offers several aspects as its constituents (see, e.g., $[21,24,25])$, like the modelling procedure or modelling method, the result of modelling (i.e. the model), the tool support, and the organizational structures establishing modelling within an organization. However, not all scholars in the field agree on all of the above EM constituents. Some researchers consider constructional and functional structures as part of modelling methods and argue that this cannot be separated [26]. Others emphasize the importance of meta-models and modelling languages for capturing different perspectives [27]. Tool support is often seen as inseparable manifestation of modelling approaches and notations [28], but in other research work as aid to support modelling [21]. Organizational structures and role descriptions are often neglected in EM approaches.

Due to this plethora of topics and concepts, a recent study among EM experts suggests that one of the most important topics of future research is EM simplification: "To a great extent, this can be explained in that the variety of different components [...] exhibit a high degree of complexity of the subject area, which needs to be reduced in future research efforts" [29].

Knowledge Management

Knowledge engineering [30] and enterprise knowledge modelling [31] contribute to systematic development and reuse of knowledge by offering methods, tools and approaches for capturing knowledge in defined representations in order to support the entire lifecycle of organizational knowledge management [32]. Inspiration for implementing the vision of "modelling for the masses" comes from (organizational and technical) knowledge management. Knowledge management from an organizational perspective addresses how to establish systematic knowledge management in an organization in terms of activities and organizational structures required. Well-known approaches in this area are the "building block" model [33] and the SECI model [34]. IT-based knowledge management systems are support for organizational knowledge management. In this area, Maier et al.'s architecture proposal [35] for such systems and the differentiation between various knowledge services as components of this architecture are often applied. Knowledge reuse in general addresses techniques and approaches for preparing knowledge for reuse in different contexts. Existing work is categorized and structured in [36]. Organizational situations for knowledge reuse were identified by Markus [37]. Knowledge about these situations supports the design of tools and organizational practices.

Semantic Web

The concept of a "semantic web", which originated from the vision that machines are enabled to conduct automated reasoning and can thus infer information from 
resources on the world-wide-web [38], led to a number of research efforts in regard to EM. In contrast to semi-formal approaches in the area of conceptual modeling that primarily build on a formal syntax with semantic expressed in natural language [39], approaches based on semantic web technologies typically strive for logic-based models that enable automated processing [40]. The spectrum of using semantic web technologies in EM thereby stretches from the use of distinct ontology languages for describing enterprise models, e.g., [41], to the transformation of enterprise models to formal ontologies, e.g., [42], up to the lightweight approaches of using semantic annotations for processing enterprise model content, e.g., [43]. New standards and vocabularies for open data exchange mean that open semantic data may in the future increasingly overlap with EM. They offer new uses of enterprise models for new types of users. For example, open semantic data sets can be used both for enriching and mining enterprise models, and enterprise models can be used to help users by making sense of, providing context for and offering access to semantically annotated information relevant to an enterprise. The research challenge is to connect the implicit, but often tacit, semantic assumptions made in enterprise models and EM languages to link them to the bottom-up web of semantically annotated data where anyone can contribute anything about any topic using their preferred vocabulary [44]. Research on these aspects has to combine approaches from traditional conceptual enterprise modeling with techniques primarily found in areas such as artificial intelligence, semantic web, and linked data.

\section{Legal Visualization}

From the field of legal visualization and legal modelling, insights can be gained on the representation of legal information in the form of models and how this can serve for enhancing the expert-lay communication [45]. Examples include the model-based representation of legal options in hereditary law [46] or the use of UML for depicting legal language relationships [47]. From these examples it can be inferred also for other areas of EM how non-experts may be addressed, thus opening the potential user base of such models.

\subsection{Practice Oriented Approaches}

Practice Theory and Computer Supported Cooperative Work Organizational research [48, 49] and workplace studies [50] have taken a "practice turn" in recent years. While there is no coherent "practice theory", researchers can learn from philosophers (Heidegger, Marx, Wittgenstein) and sociologists (Bourdieu, Giddens) that human actual practices are fundamental to a human identity and cognition and are an essential building block in understanding higher level concepts like organizations, power and knowledge [51]. Studying practices leads to an understanding what human actors really do, how they make sense of what they do and how they communicate this knowledge to others. This perspective has appealed to researchers of Computer Supported Cooperative Work who wanted to understand frequent failures and unexpected obstacles in adopting collaborative technologies in the field (see e.g., $[52,53]$ ). Typically, those workplace studies have a focus on how artefacts (traditional or digital) are embedded in human activities, e.g., as a tool, as material, as knowledge repository or as symbol. We see a great potential in applying 
the tool set of practice theory to enterprise modelling. The study of Enterprise Modelling Practices enhances our understanding what both modelling laymen and expert really do, when they model, what the role of modelling artifacts really is, how several actors collaborate in modelling or using models, how Enterprise Modelling Practices blend into their other work practices, and how structures like power and information flows are shaped by EM Practices. For example, this approach can help to understand why PowerPoint has been so widely adopted for modelling purposes [54].

\section{Architectural Thinking}

As an alternative approach to top-down, governance-based EM, the concept of architectural thinking (AT) has been proposed [3,6]. AT is understood as the way of thinking and acting throughout an organization, i.e. not restricted to architects and system developers, that considers holistic, long-term system aspects as well as fundamental system design and evolution principles in day-to-day decision making (e.g., change requests). A traditional approach to implement AT is to 'bring architecture to the business', i. e. to build up modeling and model-based analysis competences and responsibilities in business lines (and not in a central architecture unit or in the IT unit), thereby enabling many additional people in the organization to 'architecturally think and act'. As many organizations however failed to motivate business lines to 'architecturally think and act', research has been addressing the creation of enabling conditions for AT. Weiss et al. [55] adopted institutional theory as a lens to analyze the obvious reluctance of many organizational actors to comply with enterprise-wide norms and guidelines. They show that social legitimacy, efficiency, organizational grounding and trust have significant influence on the actor's response towards "restriction of design freedom" [56] and propose that, as a consequence, supportive conditions need to be created in the form that

- actors gain social fitness inside the organization when complying with architectural guidelines (social legitimacy),

- $\quad$ actors become more efficient when following guidelines (efficiency),

- $\quad$ architecture management is anchored within the organization's values in terms of strategy definition, top management support or the position in the organizational hierarchy (organizational grounding), and

- $\quad$ actors are confident that the architecture does the right things right (trust).

While governance-based architecture management cannot directly 'create' AT, it can create conditions under which AT is more likely to develop and sustain.

\subsection{Approaches with Relevance to Tool Support}

\section{Gamification}

One direction of modelling research has been concerned with the process of modelling: understanding it, but most of all making models and modelling easier, more accessible for stakeholders more 'usable' [57], even more engaging. Inquiries into the process or act of modelling indicate that workflow-based approaches cannot adequately and usefully capture or guide the iterative and unpredictable process of modelling in its operational detail. Alternatively, modelling processes can be framed as games [58, 59, 60]. Essential 'modelling game elements' and 'game mechanics' constitute dialogue games. The core of such games (typically collaborative in nature) 
are conversational moves in which modelers propose, discuss, accept or reject model elements, while rapidly switching the specific focus of the dialogue in a goal-driven fashion $[4,60]$.

\section{Visual Languages}

The research area of visual languages is closely related to the field of EM. The focus here is the interaction of humans and machines through visual representations on computer screens [61]. Although the technical realization of visual languages in the context of EM is today often accomplished using meta modelling platforms such as Eclipse-EMF, MetaEdit, or ADOxx, the theories and innovative approaches developed in visual language research can be very valuable. Examples include the technique of visual semantic zooming recently proposed by Yoon and Myers for better understanding and interacting with changes in program code [62] or approaches for recording, processing, and visualizing changes in diagrams [63].

\section{Collaborative Working Environments}

From enterprise architecture management (EAM), experiences and practices of model-based collaboration environments supporting collaborative bottom-up modelling can contribute to the vision presented in Section 3. EAM addresses the immanent need for mutual alignment of business and IT in enterprises to react upon frequently changing market conditions [64]. It seeks to capture and manage a holistic view of the enterprise to strategically plan enterprise transformations with respect to both, business and IT concerns [56]. [65] describes the underlying approach of the model-based working environment how it empowers information carriers and enterprise architects to collaboratively and incrementally develop and manage a model in a bottom-up fashion by using wiki pages enriched with types and attributes. In practicing EAM, multiple stakeholders have to collaborate to achieve different predefined enterprise-related goals [64]. Additionally, they struggle with inflexible models not meeting the information demand of stakeholders or with heavy-weight tools to manage architectural information [56, 65]. In order to tackle the aforementioned challenges, the lightweight approach Hybrid Wikis was developed. This approach enables the emergent enrichment of unstructured content (e.g., free text or documents) with structure (types, attributes, and relationships) achieving a collaborative model-based collaboration environment that supports the evolution of both the user-model and its data [68, 69]. The Hybrid Wiki approach combines both modelling approaches, namely top-down modelling (model-first) and bottom-up modelling (data-first). Its goal is to empower non-expert users to collaboratively gather and consolidate information in a flexible meta-model-based information system (SocioCortex), which acts as a model-based collaboration environment for members of the organization [69].

\section{A Perspective on Challenges for Research and Practice}

In order to analyze the challenges in the context of our vision, several dimensions should be considered which also are expected to help structuring future work. Along these dimensions, a roadmap for future research in the field can be developed: 
- Stakeholder dimension: Who is creating and using models? At least four stakeholder categories have to be distinguished: Grass-root (i.e. everybody in an enterprise without any particular modelling competence create/use models on their own or in collaboration with peers), participative (participation of domain experts in modelling process led by modelling experts), expert (modelling experts create/use models), and computer (machine-generated or interpreted models, e.g., from enterprise information sources or by integration of existing models). A better understanding is required about how models or model-like content is created and used by non-traditional enterprise model users, e.g., the grass root modelers, and in local practices. This better understanding has to be used for improving model content integration into conventional modelling tools and methods. Additionally, stakeholder perceptions of 'restriction of design freedom' [70] need to be better understood in order to systematically create conditions that are favorable for decentralized EM approaches like "Architectural Thinking" [12, 7].

- Concern dimension: What role do models have for which stakeholder concerns? In order to exploit the full application potential of models, it needs to be better understood which types of concerns of which stakeholder groups can typically be supported by which types of models and which type of content. While certain classifications like strategic, tactical and operational concerns or short-term or long-term concerns were investigated, they need to be linked to stakeholder groups, use situations, and model type / content.

- Model understandability dimension: How easy to understand is the model for different stakeholders and how much is the model formalized? There are representations comparably easy to understand for certain stakeholders (e.g., visual models or tailored model views for experts) or difficult to understand (e.g., formal ontology representations for grass-root), and many levels in between these extremes. What is the meaning of the modelling constructs, the model elements and their relations? The formality of the representation is often linked to the understandability.

- Model scope dimension: In what scope is the model relevant? Categories could be that a model is relevant for individuals only, for an organization unit, a group of people with the enterprise, the enterprise as a whole, or an ecosystem of organizations.

- Model processing dimension: What tasks have to be supported across different model representations, scopes, purposes and local practices? Examples for such tasks are alignment, visualization, ambiguity detection, approximation (find similar models), annotating or linking. How can different models be semantically integrated and processed? To what extent do semantics need to be integrated or, otherwise posted, what extent of ambiguity can be accepted by an organization? How can the semantics of models be gradually evolved?

- Value and quality dimension: Which factors affect quality, success, failure, utility of modelling? How is it related to semantic vocabularies and other semantic standards? How are other information sources linked to models?

- Model lifecycle dimension: What phases of model lifecycles have to be distinguished? Are these lifecycle phases different for different model kinds 
and do they show different paces? What formal constraints are there on the information?

We propose to use the above dimensions for structuring the challenges to be addressed for achieving the vision. In Table 1, the dimensions are put in relation to the vision's aspects identified in Section 3. This allows for systematic identification of topics for future research. As an initial step, the areas discussed in Section 4 were analyzed for relevant topics. The identified topics were positioned in Table 1 according to the aspect of the vision and the dimension they address.

Table 1: Research topics relevant for attaining the vision

\begin{tabular}{|c|c|c|c|c|c|c|c|}
\hline $\begin{array}{l}\text { Dimen- } \\
\text { sion } \\
\text { Vison's } \\
\text { Aspect }\end{array}$ & $\begin{array}{l}\text { Stake- } \\
\text { holders }\end{array}$ & $\begin{array}{l}\text { Model } \\
\text { represen- } \\
\text { tation }\end{array}$ & $\begin{array}{l}\text { Model } \\
\text { scope }\end{array}$ & Purpose & $\begin{array}{l}\text { Process- } \\
\text { ing }\end{array}$ & $\begin{array}{l}\text { Value \& } \\
\text { Quality }\end{array}$ & $\begin{array}{l}\text { Life- } \\
\text { cycle }\end{array}$ \\
\hline $\begin{array}{l}\text { Modell- } \\
\text { ing is } \\
\text { em- } \\
\text { bedded } \\
\text { in } \\
\text { everyday } \\
\text { work }\end{array}$ & $\begin{array}{l}\text { Under- } \\
\text { standing } \\
\text { grass root } \\
\text { model use } \\
\text { and } \\
\text { creation, } \\
\text { improve } \\
\text { social } \\
\text { legitimacy }\end{array}$ & $\begin{array}{l}\text { Model- } \\
\text { generated } \\
\text { workspace, } \\
\text { model } \\
\text { visuali- } \\
\text { zation }\end{array}$ & $\begin{array}{l}\text { Model } \\
\text { views, } \\
\text { simplific } \\
\text { ation of } \\
\text { EM } \\
\text { methods }\end{array}$ & $\begin{array}{l}\text { Interactiv } \\
\text { e model } \\
\text { support }\end{array}$ & $\begin{array}{l}\text { Integrate } \\
\text { model- } \\
\text { ling tools } \\
\text { and plat- } \\
\text { forms in } \\
\text { enterprise } \\
\text { environ- } \\
\text { ments }\end{array}$ & $\begin{array}{l}\text { Comprehe } \\
\text { nsion of } \\
\text { 'just } \\
\text { sufficient' } \\
\text { models }\end{array}$ & $\begin{array}{l}\text { Model at } \\
\text { run-time, } \\
\text { from ad- } \\
\text { hoc } \\
\text { model to } \\
\text { elaborate } \\
\text { d model }\end{array}$ \\
\hline $\begin{array}{l}\text { Model } \\
\text { combi- } \\
\text { nation, } \\
\text { integra- } \\
\text { tion, } \\
\text { federa- } \\
\text { tion on } \\
\text { demand }\end{array}$ & $\begin{array}{l}\text { Semantic } \\
\text { enrichment } \\
\text { when } \\
\text { maturing } \\
\text { models }\end{array}$ & $\begin{array}{l}\text { Semantic } \\
\text { aspects of } \\
\text { model } \\
\text { representati } \\
\text { on }\end{array}$ & $\begin{array}{l}\text { Going } \\
\text { from } \\
\text { local to } \\
\text { global } \\
\text { scope }\end{array}$ & $\begin{array}{l}\text { Model } \\
\text { integratio } \\
\mathrm{n}, \\
\text { support } \\
\text { of reuse } \\
\text { situations }\end{array}$ & $\begin{array}{l}\text { Understan } \\
\text { ding } \\
\text { model } \\
\text { seman- } \\
\text { tics by } \\
\text { intelli- } \\
\text { gent } \\
\text { agents }\end{array}$ & $\begin{array}{l}\text { Manual } \\
\text { and } \\
\text { automatic } \\
\text { quality } \\
\text { assurance } \\
\text { of models }\end{array}$ & $\begin{array}{l}\text { Model } \\
\text { federa- } \\
\text { tion and } \\
\text { integra- } \\
\text { tion life- } \\
\text { cycle, } \\
\text { value of } \\
\text { models }\end{array}$ \\
\hline $\begin{array}{l}\text { Specific } \\
\text { but } \\
\text { integra- } \\
\text { tive local } \\
\text { practices }\end{array}$ & $\begin{array}{l}\text { Light- } \\
\text { weight } \\
\text { practices } \\
\text { for local } \\
\text { workers. } \\
\text { simplificati } \\
\text { on of EM } \\
\text { tool }\end{array}$ & $\begin{array}{l}\text { Local } \\
\text { representati } \\
\text { ons, } \\
\text { semantic } \\
\text { annotations } \\
\text {, DSML }\end{array}$ & $\begin{array}{l}\text { Local } \\
\text { practice, } \\
\text { models } \\
\text { as } \\
\text { boundary } \\
\text { objects }\end{array}$ & $\begin{array}{l}\text { Sense- } \\
\text { making } \\
\text { and local } \\
\text { communi } \\
\text { cation }\end{array}$ & $\begin{array}{l}\text { Visualizat } \\
\text { ion, } \\
\text { sematic } \\
\text { integra- } \\
\text { tion of } \\
\text { models + } \\
\text { docu- } \\
\text { ments } \\
\end{array}$ & $\begin{array}{l}\text { Model } \\
\text { comprehe } \\
\text { nsion and } \\
\text { stake- } \\
\text { holder } \\
\text { agreement }\end{array}$ & $\begin{array}{l}\text { Projects } \\
\text { and work } \\
\text { tasks, } \\
\text { know- } \\
\text { ledge } \\
\text { services } \\
\text { for EM }\end{array}$ \\
\hline $\begin{array}{l}\text { Grass- } \\
\text { root and } \\
\text { professi- } \\
\text { onal } \\
\text { modell- } \\
\text { ing in } \\
\text { synergy }\end{array}$ & $\begin{array}{l}\text { Practices } \\
\text { for expert } \\
\text { modelers } \\
\text { and local } \\
\text { workers }\end{array}$ & $\begin{array}{l}\text { Transition } \\
\text { between } \\
\text { light- and } \\
\text { heavy- } \\
\text { weight } \\
\text { modelling } \\
\text { approach } \\
\end{array}$ & $\begin{array}{l}\text { Organizat } \\
\text { ional } \\
\text { practice }\end{array}$ & $\begin{array}{l}\text { Alignme } \\
\mathrm{nt} \text { of } \\
\text { local } \\
\text { practices }\end{array}$ & $\begin{array}{l}\text { Semantic } \\
\text { enrichmen } \\
\mathrm{t}, \text { model } \\
\text { merging }\end{array}$ & $\begin{array}{l}\text { Model } \\
\text { availabilit } \\
\text { y using } \\
\text { agreed } \\
\text { syntax }\end{array}$ & $\begin{array}{l}\text { Organizat } \\
\text { ional } \\
\text { memory }\end{array}$ \\
\hline $\begin{array}{l}\text { Softened } \\
\text { require- } \\
\text { ments to } \\
\text { complete } \\
\text { ness, } \\
\text { rigor }\end{array}$ & $\begin{array}{l}\text { Local } \\
\text { workers, } \\
\text { modeling } \\
\text { games }\end{array}$ & $\begin{array}{l}\text { Local } \\
\text { representati } \\
\text { ons, } \\
\text { multiple } \\
\text { stakeholder } \\
\text { environmen } \\
\text { ts }\end{array}$ & $\begin{array}{l}\text { Local } \\
\text { practice, } \\
\text { hybrid } \\
\text { models/m } \\
\text { ethods/to } \\
\text { ols }\end{array}$ & $\begin{array}{l}\text { Sense- } \\
\text { making } \\
\text { and local } \\
\text { comm., } \\
\text { limited } \\
\text { degree of } \\
\text { enterprise } \\
\text { wide in- } \\
\text { tegration }\end{array}$ & $\begin{array}{l}\text { Process } \\
\text { unstruc- } \\
\text { tured } \\
\text { model } \\
\text { content, } \\
\text { e.g. NLP, } \\
\text { document } \\
\text { and EM } \\
\text { mining } \\
\end{array}$ & $\begin{array}{l}\text { Model } \\
\text { comprehe } \\
\text { nsion and } \\
\text { stakehold } \\
\text { er } \\
\text { agreement }\end{array}$ & $\begin{array}{l}\text { Short- } \\
\text { term } \\
\text { projects } \\
\text { and local } \\
\text { work } \\
\text { tasks }\end{array}$ \\
\hline
\end{tabular}




\section{Summary and Future Work}

Starting from a brief analysis of problems in EM this paper proposed a vision for the future of the field which can be summarized as "modelling for and by the masses" and aims at better exploiting the potential of EM from an enterprise perspective. Furthermore, we identified research topics to be investigated on mid-term and longterm which form the basis for a research roadmap. Future work will have to focus on elaborating a research roadmap and on initiating research work required for attaining the vision. An important precondition is discussion of the vision and its consequences in the enterprise modeling community.

Many of the raised issues and open concerns are related to better understanding how people use models, what concerns they have, with whom they need to communicate, etc. Better understanding is often not sufficiently achievable only by eliciting (model engineering) requirements, but needs to connect to behavioral research that provides insights on motivations, perceptions, concerns, and emergence. This calls not necessarily for a methodological evolution of the EM discipline, but for a better integration with other (IS) research communities that could provide such insights. With such foundations, new innovative approaches to modeling, humanmodel interaction and the processing of information contained in models can be ultimately developed and shared across communities.

\section{Acknowledgements}

This paper is a result of the Dagstuhl seminar no. 16192 on „Supporting Organizational Efficiency and Agility: Models, Languages and Software Systems“ (see http://www.dagstuhl.de/de/programm/kalender/semhp/?semnr=16192).

\section{References}

1. Zdravkovic, J.; Stirna, J.; Kirikova, M.; Karagiannis, D.; Winter, R. (2015) Advanced Enterprise Modeling. BISE; Vol. 57, Issue 6; Springer, 2015.

2. Frank, U.; Strecker, S.; Fettke, P.; vom Brocke, J.; Becker, J.; Sinz, E.(2014) The Research Field "Modeling Business Information Systems" - Current Challenges and Elements of a Future Research Agenda. BISE; Vol. 6, Issue 1; Springer, 2014.

3. Hoppenbrouwers, S.J.B.A, B. Schotten, and P.J.F. Lucas: Towards Games for Knowledge Acquisition and Modeling. In: International Journal of Gaming and Computer-Mediated Simulations, Oct-Dec.2010, Vol. 2, No. 4. Special issue on AI and Games. IGI Global.

4. Hoppenbrouwers, S.J.B.A and Wilmont, I.: Focused Conceptualisation: Framing Questioning and Answering in Model-Oriented Dialogue Games. In: Bommel, P. van, Hoppenbrouwers, S.J.B.A., Overbeek, S., Proper, H.A., and Barjis, J.: Proceedings of the Third IFIP WG 8.1 Working Conference on the Practice of Enterprise Modeling (PoEM 2010), held November 9-10 in Delft, the Netherlands. LNBIP 68. Berlin: Springer, 2010.

5. Hermans FFJ (2012) Analyzing and Visualizing Spreadsheets. PhD thesis, Software Engineering Research Group, Delft University of Technology, The Netherlands.

6. Winter, R.: Architektur braucht Management, in: Wirtschaftsinformatik, 46, 4, 2004, S. 317-319.

7. Winter, R.: Architectural Thinking, in: Business \& Information Systems Engineering, 6, 6, 2014, pp. 361-364. 
8. Fossland, S. and Krogstie, J. Modeling As-is, Ought-to-be and To-be - Experiences from a Case study in the Health Sector PoEM 2015 Valencia Spain.

9. Theunissen, T.; van Heesch, U. (2016): The Disappearance of Technical Specifications in Web and Mobile Applications. In: Proceedings of the 10TH European Conference on Software Architecture (ECSA), September 2016, Copenhagen, Denmark. [to appear]

10. Star, S.; Griesemer, J.: Institutional Ecology, 'Translations' and Boundary Objects: Amateurs and Professionals in Berkeley's Museum of Vertebrate Zoology, 1907-39, in: Social Studies of Science, 19, 3, 1989, pp. 387-420.

11. Aier S, Riege C, Winter R (2008) Unternehmensarchitektur - Literaturüberblick und Stand der Praxis. Wirtschaftsinformatik 50 (4), pp. 292-304.

12. Ross JW, Quaadgras A (2012) Enterprise Architecture Is Not Just for Architects. Center for Information Systems Research Sloan School of Management Massachusetts Institute of Technology

13. Gardner D, Fehskens L, Naidu M, Rouse WB, Ross JW (2012) Point-Counterpoint: Enterprise Architecture and Enterprise Transformation as Related but Distinct Concepts. Journal of Enterprise Transformation 2 (4), pp. 283-294.

14. Krogstie, J. Quality in Business Process modeling, Springer 2016)

15. Weick, K. 1995. Sensemaking in Organisations. London: Sage.

16. Heggset, J. Krogstie and H. Wesenberg, (2015) "Understanding Model Quality Concerns when Using Process Models in an Industrial Company" In Proceedings from EMMSAD 2015. Springer.

17. Krogstie, B.R,; Schmidt, A.P.; Kunzmann, C.; Krogstie, J.; Mora, S. (2013) Linking Reflective Learning and Knowledge Maturing in Organizations. Proc. ARTEL 2013.

18. Krogstie, J, Dalberg, V., Jensen, S. M.: Process modeling value framework. In Yannis Manolopoulos, Joaquim Filipe, Panos Constantopoulos \& Jose Cordeiro (Eds.), Selected papers from 8th International Conference, ICEIS 2006 (Vol. LNBIP 3, pp. 309-321). Paphos, Cyprus: Springer. (2008)

19. Krogstie, J.; Jørgensen, H. (2002) Quality of Interactive Models. First International Workshop on Conceptual Modelling Quality (IWCMQ'02), Tampere, Finland (2002)

20. Vernadat, F. B.: Enterprise Modelling and Integration. Chapman \& Hall, 1996.

21. Sandkuhl, K.; Stirna, J.; Persson, A. and M. Wißotzki: Enterprise Modeling: Tackling Business Challenges with the 4EM Method (The Enterprise Engineering Series). Springer Verlag, Berlin Heidelberg, 2014. ISBN 978-3662437247.

22. Stirna, J., Persson, A., \& Sandkuhl, K. (2007). Participative enterprise modeling: experiences and recommendations. In International Conference on Advanced Information Systems Engineering (pp. 546-560). Springer Berlin Heidelberg.

23. Van Deursen, A., Klint, P., \& Visser, J. (2000). Domain-Specific Languages: An Annotated Bibliography. Sigplan Notices, 35(6), 26-36.

24. Henderson-Sellers, B., Ralyté, J., Ågerfalk, P. J., \& Rossi, M. (2014). Situational Method Engineering (pp. 1-274). Springer.

25. Frank, U. (2014) Multilevel Modeling - Toward a New Paradigm of Conceptual Modeling and Information Systems Design. Business \& Information Systems Engineering 6(6): 319 337 (2014).

26. Dietz JLG (2006) Enterprise ontology - theory and methodology. Springer, Heidelberg

27. Frank U (2014) Multi-perspective enterprise modeling: foundational concepts, prospects and future research challenges. Softw Syst Model 13(3):941-962. doi:10.1007/s10270012-0273-9.

28. ISO/IEC 24744 (2014) Software Engineering -- Metamodel for Development Methodologies. http://www.iso.org/iso/home/store/catalogue_ics/ catalogue_detail_ics.htm?csnumber=62644 
29. Wirtz, Bernd W., Pistoia, Adriano, Ullrich, Sebastian, Göttel, Vincent (2016): Business Models: Origin, Development and Future Research. In Long Range Planning, Vol. 49, S. $36-54$.

30. Studer, R., Benjamins, V. R., \& Fensel, D. (1998). Knowledge engineering: principles and methods. Data \& knowledge engineering, 25(1), 161-197.

31. Lillehagen, F.; Krogstie, J. (2009) Active Knowledge Modelling of Enterprises. Springer, 2009. ISBN: 978-3-540-79415-8.

32. Dalkir, K. (2013). Knowledge management in theory and practice. Routledge.

33. Probst, G., Raub, S., Romhardt, K. (2000) Managing Knowledge - Building Blocks for Success. John Wiley \& Sons, Chichester, UK (2000).

34. Nonaka, I. (1994) A Dynamic Theory of Organizational Knowledge Creation. Organization Science, Vol. 5, No. 1 (Feb., 1994), pp. 14-37.

35. Maier, R., Hädrich, T., Peinl, R. (2010): Enterprise Knowledge Infrastructures, 2nd Edition. Springer, 2010.

36. Sandkuhl, K. (2015). Knowledge Reuse: Survey of Existing Techniques and Classification Approach. Business Intelligence, LNBIP 205, pp. 126-148, Springer.

37. Markus, M. Lynne. 2001. Toward a Theory of Knowledge Reuse: Types of Knowledge Reuse Situations and Factors in Reuse Success, Journal of Management Information Systems, 18, 1 (Summer): 57-93.

38. Berners-Lee, T., J. Hendler, et al. (2001). "The Semantic Web - A new form of Web content that is meaningful to computers will unleash a revolution of new possibilities." Scientific American May 2001.

39. Fraser, M. D., K. Kumar, et al. (1994). "Strategies for incorporating formal specifications in software development." Communications of the ACM 37(10): 74-86.

40. Obrst, L. (2003). Ontologies for semantically interoperable systems. Proceedings of the 12th International Conference on Information and Knowledge Management, New Orleans, ACM Press.

41. Tarassov, V., K. Sandkuhl, et al. (2006). Using ontologies for representation of individual and enterprise competence models. International Conference on Research, Innovation and Vision for the Future IEEE.

42. Thomas, O. and M. Fellmann (2007). "Semantic Business Process Management: Ontology-based Process Modeling Using Event-Driven Process Chains." IBIS 2(1): 29-44.

43. Fill, H.-G. (2011). On the Conceptualization of a Modeling Language for Semantic Model Annotations. Advanced Information Systems Engineering Workshops, CAiSE 2011. C. Salinesi and O. Pastor. London, UK, Springer. LNBIP Vol. 83: 134-148.

44. Allemang, D.; Hendler, J. (2011) Semantic web for the working ontologist: effective modeling in RDFS and OWL. Elsevier, 2011.

45. Brunschwig, C. (2012): Multisensory Law and Therapeutic Jurisprudence: How Family Mediators Can Better Communicate with Their Clients, Phoenix Law Review, Vol. 5, No. 4, 705-746.

46. Fill, H.-G., Haiden, K. (2016): Visuelle Modellierung für rechtsberatende Berufe am Beispiel der gesetzlichen Erbfolge, Jusletter IT, 25. February 2016, Weblaw.

47. Engesser, M. (2014): UML und Sprache - Wirklichkeit und Technik, Jusletter IT, September 2014, Weblaw.

48. Corradi, Gessica, Silvia Gherardi, and Luca Verzelloni. "Through the practice lens: where is the bandwagon of practice-based studies heading?." Management learning 41.3 (2010): 265-283.

49. Schatzki, Theodore R. "Practice minded orders." The practice turn in contemporary theory 11 (2001).

50. Luff, Paul, Jon Hindmarsh, and Christian Heath. Workplace studies: Recovering work practice and informing system design. Cambridge university press, 2000. 
51. Nicolini, Davide. Practice theory, work, and organization: An introduction. Oxford university press, 2012.

52. Heath, Christian, and Paul Luff. "Collaboration and controlCrisis management and multimedia technology in London Underground Line Control Rooms." Computer Supported Cooperative Work (CSCW) 1.1-2 (1992): 69-94.

53. Luff, Paul, and Christian Heath. "Mobility in collaboration." Proceedings of the 1998 ACM conference on Computer supported cooperative work. ACM, 1998.

54. Ciriello, Raffaele F., Alexander Richter, and Gerhard Schwabe. "PowerPoint Use and Misuse in Digital Innovation." ECIS2015 Proceedings (2015).

55. Weiss S.; Aier S.; Winter R. (2013) Institutionalization and the Effectiveness of Enterprise Architecture Management. In: 2013 International Conference on Information Systems (ICIS 2013). Association for Information Systems, Milano, 2013.

56. Roth, S., Hauder, M., Matthes, F. (2013) Collaborative Evolution of Enterprise Architecture Models. 8th International Workshop on Models at Runtime (Models@run.time 2013), Miami, USA, 2013.

57. Oppl, S. (2016) Towards scaffolding collaborative articulation and alignment of mental models. Proceedings of ICKM 2016. Elsevier Procedia Computer Science (2016)

58. Hoppenbrouwers, S.J.B.A, P. van Bommel, and Aki Järvinen. Method Engineering as Game Design: an Emerging HCI Perspective on Methods and CASE Tools. In: Proceedings of EMMSAD'08 at CAiSE'08. Montpellier, France, June 2008

59. Ssebuggwawo, D.; Stijn Hoppenbrouwers and Erik Proper: Interactions, Goals and Rules in a Collaborative Modelling Session. In: Anne Persson, Janis Stirna (eds): The Practice of Enterprise Modeling, PoEM 2009. Springer, LNBIP series vol. 3

60. Hoppenbrouwers, S.J.B.A and E.A.J.A. Rouwette: A Dialogue Game for Analysing Group Model Building: Framing Collaborative Modelling and its Facilitation. In: R. Magalhaes (ed.), International Journal of Organisational Design and Engineering (IJODE), vol. 2, no. 1, p19-40; special issue on collaborative modeling. New York, USA: Inderscience, 2012

61. Narayanan, N.H. and R. Hübscher, Visual Language Theory: Towards a Human-Computer Interaction Perspective. In: Marriott. K. (Ed.) Visual language theory. 1998, Springer: New York.

62. Yoon, Y. and B. Myers. Semantic Zooming of Code Change History. in IEEE Symposium on Visual Languages and Human-Centric Computing. 2015. IEEE.

63. Maier, S. and M. Minas. Recording, Processing, and Visualizing Changes in Diagrams. in IEEE Symposium on Visual Languages and Human-Centric Computing. 2015. IEEE.

64. Ross, J.; Weill, P.; Robertson, D..(2006) Enterprise architecture as strategy: Creating a foundation for business execution. Harvard Business Press, 2006.

65. Matthes, F.; Neubert, C. and Schneider, A. W. (2013) Fostering Collaborative and Integrated Enterprise Architecture Modeling. In Journal of Enterprise Modelling and Information Systems Architectures, Vol. 8, No. 1, March 2013.

66. Reschenhofer, T.; Monahov, I.; and Matthes, F. (2014) Application of a Domain-Specific Language to Support the User-Oriented Definition of Visualizations in the Context of Collaborative Product Development. In: Enterprise Interoperability: I-ESA'14, France.

67. Matthes F.; Neubert C. (2014) Wiki4EAM: Using Hybrid Wikis for Enterprise Architecture Management. In: 7th International Symposium on Wikis and Open Collaboration (WikiSym), Mountain View California, 2011.

68. Monahov, I. (2014) Integrated software support for quantitative models in the domain of Enterprise Architecture Management, PhD thesis, Technische Universität München, 2014.

69. Reschenhofer, T.; Bhat, M.; Hernandez-Mendez, A.; Matthes, F. (2016) Lessons Learned in Aligning Data and Model Evolution in Collaborative Information Systems. In: Proc. International Conference on Software Engineering (ICSE), Austin, Texas USA, 2016

70. Dietz J.L.G. (2008) Architecture. Building strategy into design. Academic Service, The Hague 2008. 